\title{
The association of health-related factors with quality of life among the elderly population in the Jaffna district of Sri Lanka
}

\author{
Sathees Santhalingam ${ }^{1 *} \mathbb{D}$, Sivayogan Sivagurunathan², Shamini Prathapan², Sivapalan Kanagasabai ${ }^{3}$ and
} Luxmi Kamalarupan ${ }^{1}$

\begin{abstract}
Background: The proportion of elderly individuals is increasing globally. They should be well cared for to enable them to enjoy their full lifespans. Good health is a vital component of one's overall quality of life. Our study aimed to assess the association of health-related factors with quality of life among elderly individuals in the Jaffna District of Sri Lanka.
\end{abstract}

Methods: We conducted a community-based, cross-sectional study among 813 elderly individuals in the Jaffna district of Sri Lanka. Sociodemographic factors and the patterns of health conditions were recorded through an interviewer-administered questionnaire. Quality of life was measured through the World Health Organisation Quality of Life-Bref (WHOQOL-Bref) questionnaire.

Results: There were slightly more male respondents (53.5\%) than females in the study. The median age of the participants was 70 (11) years. Approximately one-third of them had at least one chronic health condition. Musculoskeletal complaints were found to be the most common health condition, followed by diabetes, hypertension, vision problems, and asthma. Among the respondents, $20.1 \%$ were attending regular follow-up visits in a clinic, and $24 \%$ of them were meeting a doctor at least monthly. Among them, $6.8 \%$ had at least one limitation in their activities of daily living. However, the majority (58.6\%) reported that they were satisfied with their health status. The following factors were found to be significantly associated with worse quality of life: the presence of health conditions, the presence of musculoskeletal conditions, hearing impairment, vision impairment, bronchial asthma, limitations in activities of daily living, and the use of addictive substances. Satisfaction with health, regular follow-up visits in a clinic, meeting a doctor at least monthly, and having diabetes were significantly associated with better quality of life.

Conclusion: Minimising the limitations of daily living, abstaining from using addictive substances, preventing diseases, and improving access to health services may enhance the quality of life of elderly individuals. Furthermore, these factors should be considered by policy makers seeking to improve the quality of life of elderly individuals.

Keywords: Quality of life, Health, Elderly, Sri Lanka

\footnotetext{
* Correspondence: sathees@univ.jn.ac.lk

'Department of Nursing, Faculty of Allied Health Sciences, University of Jaffna, Jaffna, Sri Lanka

Full list of author information is available at the end of the article
}

(C) The Author(s). 2021 Open Access This article is licensed under a Creative Commons Attribution 4.0 International License, which permits use, sharing, adaptation, distribution and reproduction in any medium or format, as long as you give appropriate credit to the original author(s) and the source, provide a link to the Creative Commons licence, and indicate if changes were made. The images or other third party material in this article are included in the article's Creative Commons licence, unless indicated otherwise in a credit line to the material. If material is not included in the article's Creative Commons licence and your intended use is not permitted by statutory regulation or exceeds the permitted use, you will need to obtain permission directly from the copyright holder. To view a copy of this licence, visit http://creativecommons.org/licenses/by/4.0/ The Creative Commons Public Domain Dedication waiver (http://creativecommons.org/publicdomain/zero/1.0/) applies to the data made available in this article, unless otherwise stated in a credit line to the data. 


\section{BACKGROUND}

The life expectancy of humans has been increasing worldwide [1] due to the following factors: (a) the rapid advancement of health services, leading to improved standards of living; (b) healthy dietary practices; (c) increased levels of physical activity; and (d) the cessation of smoking and alcohol consumption $[2,3]$. At the same time, the global fertility rate has decreased. This has led to an increase in the global elderly population $[1,4,5]$. In most countries, a person who is over 60 years of age is considered to be elderly [6].

Currently, two-thirds of the elderly population worldwide live in developing countries [7]. The United Nations predicts that eight out of 10 elderly individuals will live in developing countries by 2050 [8]. Among the different Southeast Asian countries, Sri Lanka currently has a relatively high proportion of elderly individuals and is predicted to continue to have a relatively high proportion [9]. The proportion of elderly individuals was reported to be 1 in 10 in 2000, and this proportion increased to 1 in 5 by 2010 [10]. Additionally, the median age of the Sri Lankan population is expected to increase from 26.9 to 39.2 years between 2000 and 2030 [10]. The rapidity of population ageing has been attributed to the large demographic transition in the country [11, 12]. The growing elderly population is gradually replacing the younger population; therefore, the dependency ratio is expected to increase in the future [12]. As a developing country, it is clear that this could lead to significant challenges in various societal aspects [11].

The phenomenon of population ageing and the associated demographic transitions occurred concurrently with slow economic growth in Sri Lanka. This is in contrast to how the demographic shift in more developed countries has occurred during periods of rapid economic growth. Thus, Sri Lanka faces unique challenges when compared with countries in the developed world [9]. Population ageing and social transformation, as well as changes in social values, are new and growing challenges facing the Sri Lankan elderly population. Therefore, there is growing concern about this population.

Elderly individuals are at elevated risk for physical and psychological problems. The health conditions that most commonly affect elderly individuals are musculoskeletal conditions, respiratory diseases, gastrointestinal conditions, and cardiovascular conditions [13]. In Sri Lanka, common health conditions in the elderly population include hypertension, diabetes, visual and hearing impairments, arthritis, and asthma [14]. Apart from these physical problems, many elderly individuals also suffer from various psychological problems. If these health conditions are not managed well, they can affect an older person's wellbeing.
It is known that ageing and its associated changes usually negatively affect the health status of elderly individuals [15]. The following health-related factors have been found to be closely associated with worse quality of life in various past studies: (a) morbidities, (b) pain, (c) negative perceptions of medication, and (d) negative perceptions of health. In contrast, the following factors have been found to be associated with a better quality of life: (a) health service availability, (b) the absence of chronic diseases, (c) satisfaction with health, and (d) the absence of limitations of activities of daily living (ADL) [14, 16, 17].

In Sri Lanka, changes have occurred in the socioeconomic and family systems, from the extended family to the nuclear family. Therefore, many of those elderly individuals who, in the past, would have depended on their family members for care now suffer from a lack of caregivers [18]. This tends to impair the quality of care provided to elderly individuals in Sri Lanka and, in turn, leads to a variety of social, psychological, and physical problems.

It is vital to maintain the health of the elderly population not only for their own sakes but also for the wellbeing of the society as a whole. Moreover, it is clear that the availability of human and social resources positively influences the health of the elderly population [19]. It is essential to note that the currently accepted concepts of healthy elderhood and healthy ageing include not only the absence of disease but also an overall improvement in their quality of life (QOL) [19].

Quality of life is a good indicator of the health and wellbeing of the elderly population. It is a complex, broad-ranging concept that can include a person's physical health, psychological state, personal beliefs, social relationships, and relationship to salient environmental features [20].

Very few studies have been conducted on the quality of life of elderly individuals in Sri Lanka. One of the few researchers on the subject has reported that the QOL of the elderly in Sri Lanka was moderate and that it was significantly associated with healthrelated factors [18].

Jaffna District is one of the 25 administrative districts of Sri Lanka. It is in the Northern Province; it is the northernmost district of Sri Lanka, and the total population is 618,209 [21]. The majority of the population is Sri Lankan Tamils (98.9\%), followed by Muslims and Sinhalese. Agriculture is the main economy in the Jaffna district. According to the Sri Lankan Government Information Centre, a person who has surpassed 60 years of age is considered elderly in Sri Lanka [22]. The proportion of elderly individuals in Jaffna District is higher (14.1\%) [23] than that in Sri Lanka as a whole (12.4\%) [24]. 
In Jaffna, three decades of war, which ended in 2009, resulted in the rapid migration and death of younger people and increased the percentage of elderly people; this also led to a lack of caregivers [25]. Jaffna District ranks fourth among the districts of Sri Lanka with regard to the proportion of the population that is elderly. There is a relatively greater need to study the wellbeing of the elderly population in Jaffna District in the postwar period. The objective of this study was to increase the understanding of health-related factors and their influence on the quality of life of elderly residents in Jaffna District through a descriptive, cross-sectional study. It is hoped that the results of this study will facilitate the development of positive interventions to improve and maintain the desired standards for quality of life in the Jaffna District, as well as throughout Sri Lanka.

\section{Methods}

\section{Study sample and procedures}

This cross-sectional descriptive study included persons who were residents in Jaffna District and older than 60 years. Institutionalized elderly individuals, who represent only $0.45 \%$ of the elderly population in Jaffna [21], were excluded from this study, as their living arrangements and patterns of care are different from those of noninstitutionalized elderly individuals.

The prevalence of poor self-reported QOL was found to be $48 \%$ in a previous study [18]. Assuming a prevalence of $48 \%$, a precision of 0.05 , and a confidence level of $95 \%$, the sample size needed was calculated to be 384 based on the Daniel formula [26]. It was doubled to overcome the effect of the design and further increased to approximately 880 to account for a nonresponse rate of $15 \%$.

Two-stage random sampling (geographical cluster sampling technique) was applied. All Grama Niladari (GN) areas (smallest administrative units of Sri Lanka) (440) in Jaffna District were used as the sampling framework for the first stage, while elderly individuals older than 60 years in each GN area were used as the sampling framework for the second stage.

Ethics approval was obtained from the Ethics Review Committee of the Faculty of Medicine of the University of Jaffna of Sri Lanka (Ref. No-J/ERC/18/92/DR/0059).

\section{Measurements}

An interviewer-administered questionnaire was used to assess the sociodemographic characteristics and healthrelated factors. Further series of questions related to their health history and exposure to addictive substances were included. Smoking, betel chewing, and alcohol consumption were considered the use of addictive substances.
The previously validated WHOQOL-Bref questionnaire (Tamil version) was used to measure the quality of life of the elderly participants. This questionnaire evaluates the perceived QOL through 26 questions. Responses are given on a 5-point Likert scale. Questions were categorised to measure QOL in four broad domains: the physical domain, psychological domain, social domain, and environmental domain. A higher total score indicates a better QOL in all four domains in elderly individuals [27].

Data were collected during face-to-face interviews at the participants' homes. The presence or absence of the following health conditions was recorded: diabetes mellitus, hypertension, hyperlipidaemia, heart disease, musculoskeletal conditions, kidney diseases, vision impairment, hearing impairment, bronchial asthma, and any other diseases. Moreover, follow-up visits at a clinic and the frequency with which they visited a doctor were also recorded by the interviewers during the face-to-face interviews. Recall bias was considered minimal, as the information gathered was highly personal. Participants who found it difficult to recall the date of their last clinic or doctor visit were assisted in recalling it in relation to the timing of annual festivals. Individual scores for the domains of quality of life were measured. The transformed scores were calculated using the transformed score table; overall quality of life was determined based on the average of the domain scores.

\section{Statistical analysis}

All the data collected were analysed with the Statistical Package for Social Sciences (SPSS) for Windows, version 16. Both descriptive and inferential statistics were used to report the results for the sociodemographic variables, self-reported health conditions, and quality of life. The results for categorical variables are expressed as proportions and frequencies. Continuous variables are reported as the means and standard deviations.

One-way ANOVA and independent $t$-tests were used to identify the mean differences in quality of life with respect to the presence or absence of the health conditions considered in this study. Variables with a $p$-value less than 0.05 in univariate analysis were included in the multiple linear regression model, and further multicollinearity of variables was tested. This model was used to determine the independent association of the healthrelated factors with quality of life, and a $p$-value $<0.05$ was considered statistically significant.

\section{Results}

A total of 813 prospective participants consented to take part in the study, with a response rate of $92.4 \%$. The median age of the participants was 70 (11) years. The majority of the participants were the age group from 60 to 
69 years. There was a slightly higher proportion of males (53.5\%) than females. The majority of the participants were Hindu (85.9\%). Approximately two-thirds of them (61.6\%) lived with their spouse, and a small proportion (1.7\%) of them had not gone to school. Approximately half of them had never worked (47\%), 36.3\% were currently working, and $16.7 \%$ were retired from previous employment. Concerning monthly income, $54.9 \%$ had a monthly income below the national poverty line (food and non-food expenditures per person per month) (see Table 1).

Table 2 shows the quality of life scores. The overall (average) score for quality of life was $11.5 \pm 2.2$ out of 20. Regarding the different quality of life domain scores, the environmental domain was found to have the highest score $(12.1 \pm 2.1)$, followed by the psychological domain $(12.0 \pm 2.8)$, the physical domain $(11.8 \pm 2.3)$, and the social domain $(10.1 \pm 3.0)$.

Concerning the health status of the participants, $62.6 \%$ of them reported that they had at least one health condition. The most prevailing type of health condition was musculoskeletal disorders (22.3\%). This was followed by diabetes mellitus (20.7\%). The next most common conditions were hypertension (18.8\%), vision impairment $(16.2 \%)$, and asthma (9.8\%). The combination of diabetes

Table 1 Sociodemographic characteristics of the participants

\begin{tabular}{|c|c|c|c|}
\hline \multicolumn{2}{|c|}{ Sociodemographic yactors $(n=813)$} & \multirow{2}{*}{$\begin{array}{l}\mathbf{n} \\
382\end{array}$} & \multirow{2}{*}{$\frac{\%}{47 .}$} \\
\hline Age (Years) & $60-69$ & & \\
\hline & $70-79$ & 308 & 37.9 \\
\hline & 80 and above & 123 & 15.1 \\
\hline \multirow[t]{2}{*}{ Sex } & Male & 435 & 53.5 \\
\hline & Female & 378 & 46.5 \\
\hline \multirow[t]{3}{*}{ Religion } & Hindu & 685 & 85.9 \\
\hline & Christian & 107 & 13.5 \\
\hline & Islam & 05 & 0.6 \\
\hline \multirow[t]{4}{*}{ Marital status } & Unmarried & 20 & 2.5 \\
\hline & Married & 500 & 61.6 \\
\hline & Widowed & 261 & 32.2 \\
\hline & Divorced/separated & 30 & 3.7 \\
\hline \multirow[t]{5}{*}{ Education } & No schooling & 14 & 1.7 \\
\hline & Primary & 98 & 12.1 \\
\hline & Secondary & 607 & 74.7 \\
\hline & Collegial & 58 & 7.1 \\
\hline & Tertiary & 36 & 4.4 \\
\hline \multirow[t]{3}{*}{ Occupation } & Retired & 136 & 16.7 \\
\hline & Currently working & 295 & 36.3 \\
\hline & Never worked & 382 & 47.0 \\
\hline \multirow[t]{2}{*}{ Monthly income } & Below national poverty line & 384 & 54.9 \\
\hline & Above national poverty line & 315 & 45.1 \\
\hline
\end{tabular}

Table 2 Scores for QOL domains $(n=813)$

\begin{tabular}{lllll}
\hline QOL scores & Minimum & Maximum & Mean & SD \\
\hline Physical & 5.00 & 19.00 & 11.79 & 2.30 \\
Psychological & 5.00 & 19.00 & 11.97 & 2.77 \\
Social Relationship & 4.00 & 20.00 & 10.14 & 3.04 \\
Environment & 4.00 & 19.00 & 12.10 & 2.11 \\
Overall (average) score & 5.50 & 18.75 & 11.50 & 2.17 \\
\hline
\end{tabular}

mellitus and hypertension was the most common, as 86 elderly individuals had both diseases.

Among the respondents, 169 (20.9\%) were attending regular follow-up in a clinic, while $24.9 \%$ were visiting their doctor at least once a month.

The mean differences in the quality of life domain scores of the elderly individuals with various conditions are shown in Table 3. The overall quality of life score was the lowest among elderly individuals with kidney disease, followed by those with musculoskeletal conditions, hearing impairment, and visual impairment. Furthermore, overall QOL was associated with the presence of diabetes mellitus, musculoskeletal conditions, vision impairment, hearing impairment, and bronchial asthma. An independent t-test revealed that the mean differences were statistically significant.

Overall quality of life was higher in those who had no diseases, no ADL limitations, no addictive substance use, satisfaction with their health status and regular clinic and doctor follow-up visits. Table 4 shows the mean differences based on the above factors in the individual quality of life domain scores.

The details of the clinical follow-up among the elderly patients with various conditions are shown in Table 5 . The highest proportion of elderly individuals attending regular follow-up in a clinic had heart disease (83.3\%). This was followed by diabetes mellitus (69.6\%), hyperlipidaemia (62.1\%), and hypertension (54.9\%). A similar pattern was observed with regard to those who visited doctors at least once a month. The proportions were $88.9,70.2,62.1$, and $59 \%$, respectively.

Variables that were found to be associated with overall QOL with a $p$-value less than 0.05 were included in the multiple linear regression to identify whether there were independent associations with the overall QOL of elderly individuals. Clinical follow-up was removed from the regression due to multicollinearity.

Multiple linear regression revealed that the presence of specific health conditions, such as musculoskeletal conditions; ADL limitations; and exposure to addictive substances were independently associated with a reduced overall quality of life among the participants. Furthermore, satisfaction with their health, visiting a doctor at least once a month, and having diabetes mellitus were 
Table 3 Health conditions and their associations with the QOL of participants

\begin{tabular}{|c|c|c|c|c|c|c|c|}
\hline $\begin{array}{l}\text { Diseases } \\
(n=813)\end{array}$ & $\mathrm{n}$ & $\%$ & $\begin{array}{l}\text { Physical domain } \\
\text { Mean }( \pm \text { SD) }\end{array}$ & $\begin{array}{l}\text { Psychological } \\
\text { domain Mean }( \pm \text { SD) }\end{array}$ & $\begin{array}{l}\text { Social relationship } \\
\text { domain Mean }( \pm \text { SD) }\end{array}$ & $\begin{array}{l}\text { Environmental domain } \\
\text { Mean }( \pm S D)\end{array}$ & $\begin{array}{l}\text { Overall QOL } \\
\text { Mean } \pm \text { SD) }\end{array}$ \\
\hline \multicolumn{8}{|c|}{ Diabetic mellitus } \\
\hline Yes & 168 & 20.7 & $12.1(2.3)$ & $12.8(3.0)$ & 10.7 (3.3) & $12.9(2.1)$ & $12.1(2.3)$ \\
\hline No & 645 & 79.3 & $11.7(2.3)$ & $11.8(2.6)$ & $10.0(2.9)$ & $11.9(2.0)$ & $11.3(2.1)$ \\
\hline$p$-value & & & $<0.001$ & 0.048 & $p<0.001$ & 0.011 & $p<0.001$ \\
\hline \multicolumn{8}{|c|}{ Hypertension } \\
\hline Yes & 153 & 18.8 & $11.8(2.3)$ & $12.4(3.0)$ & $10.2(3.2)$ & $12.4(2.3)$ & $11.7(2.3)$ \\
\hline No & 660 & 81.2 & $11.8(2.3)$ & $11.9(2.7)$ & $10.1(3.0)$ & $12.0(2.0)$ & $11.4(2.1)$ \\
\hline$p$-value & & & 0.871 & 0.053 & 0.894 & 0.043 & 0.220 \\
\hline \multicolumn{8}{|c|}{ Hyperlipidaemia } \\
\hline Yes & 29 & 3.6 & $11.6(2.2)$ & $12.7(2.8)$ & $9.0(3.8)$ & $13.3(2.3)$ & $11.7(2.2)$ \\
\hline No & 784 & 96.4 & $11.8(2.3)$ & $12.0(2.8)$ & $10.2(3.0)$ & $12.0(2.1)$ & $11.5(2.2)$ \\
\hline$p$-value & & & 0.940 & 0.148 & 0.102 & 0.10 & 0.661 \\
\hline \multicolumn{8}{|c|}{ Heart disease } \\
\hline Yes & 18 & 2.2 & $11.1(2.3)$ & $12.8(1.7)$ & $8.9(3.3)$ & $12.4(1.3)$ & $11.3(1.7)$ \\
\hline No & 795 & 97.8 & $11.8(2.2)$ & $11.9(2.8)$ & $10.2(3.0)$ & $12.1(2.2)$ & $11.5(2.2)$ \\
\hline$p$-value & & & 0.171 & 0.182 & 0.078 & 0.481 & 0.701 \\
\hline \multicolumn{8}{|c|}{ Musculoskeletal conditions } \\
\hline Yes & 181 & 22.3 & $9.9(1.6)$ & $10.6(2.6)$ & $8.9(2.5)$ & $11.2(2.0)$ & $10.1(1.8)$ \\
\hline No & 632 & 77.7 & $12.3(2.1)$ & $12.4(2.7)$ & $10.5(3.1)$ & $12.4(2.0)$ & $11.9(2.1)$ \\
\hline$p$-value & & & $p<0.001$ & $p<0.001$ & $p<0.001$ & $p<0.001$ & $p<0.001$ \\
\hline \multicolumn{8}{|c|}{ Kidney disease } \\
\hline Yes & 7 & 0.9 & $10.3(1.8)$ & $9.4(2.6)$ & $8.9(3.1)$ & $10.6(3.1)$ & $9.8(2.4)$ \\
\hline No & 806 & 99.1 & $11.8(2.3)$ & $12.0(2.8)$ & $10.1(3.0)$ & $12.1(2.1)$ & $11.5(2.2)$ \\
\hline$p$-value & & & 0.082 & 0.015 & 0.263 & 0.054 & 0.056 \\
\hline \multicolumn{8}{|c|}{ Vision problems } \\
\hline Yes & 132 & 16.2 & $10.6(2.2)$ & $11.5(2.7)$ & $9.2(3.1)$ & $12.0(2.1)$ & $10.8(2.0)$ \\
\hline No & 681 & 83.8 & $12.0(2.2)$ & $12.1(2.8)$ & $10.3(3.0)$ & $12.1(2.1)$ & $11.6(2.2)$ \\
\hline$p$-value & & & $P<0.001$ & 0.040 & $P<0.001$ & 0.680 & $P<0.001$ \\
\hline \multicolumn{8}{|c|}{ Hearing impairment } \\
\hline Yes & 40 & 4.9 & $10.0(2.3)$ & $10.8(2.4)$ & $8.2(2.2)$ & $11.4(2.1)$ & $10.1(1.7)$ \\
\hline No & 773 & 95.1 & $11.9(2.3)$ & $12.0(2.8)$ & $10.2(3.0)$ & $12.1(2.1)$ & $11.6(2.2)$ \\
\hline$p$-value & & & $P<0.001$ & 0.003 & $P<0.001$ & 0.035 & $P<0.001$ \\
\hline \multicolumn{8}{|c|}{ Bronchial asthma } \\
\hline Yes & 80 & 9.8 & $11.0(1.9)$ & $11.8(2.8)$ & $9.5(2.6)$ & $11.7(2.2)$ & $11.0(2.0)$ \\
\hline No & 773 & 90.2 & $11.9(2.3)$ & 12.0() 2.8 & $10.2(3.1)$ & $12.1(2.1)$ & $11.6(2.2)$ \\
\hline$p$-value & & & 0.001 & 0.516 & 0.022 & 0.089 & 0.019 \\
\hline
\end{tabular}

independently associated with higher overall QOL (see Table 6).

\section{Discussion}

The current study revealed that the overall quality of life score among elderly individuals was $11.5 \pm 2.2$ out of 20 . Furthermore, the mean scores for all four individual domains seem to be low when compared to the
WHOQOL-Bref global mean scores for the elderly age group [27]. This result is comparable with similar studies previously conducted in Sri Lanka $[14,16]$.

The QOL of the elderly population was found to be associated with health-related factors such as the presence of a specific health condition, limitations in activities of daily living, exposure to addictive substances, perceived satisfaction with their health and the frequency of visiting a doctor. 
Table 4 Health-related factors and their associations with the QOL of participants

\begin{tabular}{|c|c|c|c|c|c|c|c|}
\hline Associated factors & $\mathrm{n}$ & $\%$ & $\begin{array}{l}\text { Physical domain } \\
\text { Mean }( \pm \text { SD) }\end{array}$ & $\begin{array}{l}\text { Psychological domain } \\
\text { Mean }( \pm \text { SD) }\end{array}$ & $\begin{array}{l}\text { Social relationship domain } \\
\text { Mean }( \pm \text { SD) }\end{array}$ & $\begin{array}{l}\text { Environmental domain } \\
\text { Mean }( \pm \text { SD) }\end{array}$ & $\begin{array}{l}\text { Overall QOL } \\
\text { Mean }( \pm \text { SD) }\end{array}$ \\
\hline \multicolumn{8}{|c|}{ Presence of health problem } \\
\hline Yes & 509 & 62.6 & $11.1(2.3)$ & $11.6(2.8)$ & $9.6(3.0)$ & $12.0(2.1)$ & $11.1(2.2)$ \\
\hline No & 304 & 37.4 & $13.0(1.8)$ & $12.5(2.5)$ & $11.0(2.8)$ & $12.3(2.0)$ & $12.2(2.0)$ \\
\hline$p$-value & & & $<0.001$ & $<0.001$ & $<0.001$ & 0.036 & $<0.001$ \\
\hline \multicolumn{8}{|c|}{ At least one ADL limitation } \\
\hline Yes & 55 & 6.8 & $8.4(2.5)$ & $9.8(2.5)$ & $7.2(2.0)$ & $10.8(2.0)$ & $9.1(1.7)$ \\
\hline No & 758 & 93.2 & $12.0(2.0)$ & $12.1(2.7)$ & $10.3(3.0)$ & $12.2(2.0)$ & $11.7(2.1)$ \\
\hline$p$-value & & & $<0.001$ & $<0.001$ & $<0.001$ & $<0.001$ & $<0.001$ \\
\hline \multicolumn{8}{|c|}{ Satisfaction on health status } \\
\hline Yes & 477 & 58.8 & $12.9(1.8)$ & $12.8(2.6)$ & $11.0(3.0)$ & $12.6(2.0)$ & $12.3(2.0)$ \\
\hline No & 334 & 41.2 & $10.1(1.9)$ & $10.8(2.6)$ & $8.9(2.7)$ & $11.4(2.0)$ & $10.3(1.8)$ \\
\hline$p$-value & & & $<0.001$ & $<0.001$ & $<0.001$ & $<0.001$ & $<0.001$ \\
\hline \multicolumn{8}{|l|}{ Clinic following } \\
\hline Yes & 169 & 20.9 & $12.0(2.5)$ & $13.2(2.9)$ & $10.6(3.5)$ & $13.2(2.2)$ & $12.0(2.3)$ \\
\hline No & 644 & 79.1 & $11.7(2.2)$ & $11.6(2.6)$ & $10.0(2.8)$ & $11.8(1.9)$ & $11.3(2.0)$ \\
\hline$p$-value & & & 0.143 & $<0.001$ & 0.048 & $<0.001$ & $<0.001$ \\
\hline \multicolumn{8}{|c|}{ Visiting a doctor at least monthly } \\
\hline Yes & 195 & 24.9 & $11.7(2.6)$ & $12.9(3.0)$ & $10.3(3.6)$ & $13.1(2.2)$ & $12.0(2.4)$ \\
\hline No & 589 & 75.1 & $11.8(2.1)$ & $11.6(2.6)$ & $10.1(2.8)$ & $11.8(1.9)$ & $11.3(2.0)$ \\
\hline$p$-value & & & 0.002 & $<0.001$ & 0.331 & $<0.001$ & $<0.001$ \\
\hline \multicolumn{8}{|c|}{ Addictive substance use } \\
\hline yes & 348 & 42.8 & $11.8(2.3)$ & $11.6(2.7)$ & $10.0(3.2)$ & $11.8(2.0)$ & $11.3(2.1)$ \\
\hline no & 465 & 57.2 & $11.8(2.3)$ & $12.2(2.8)$ & $10.2(2.9)$ & $12.3(2.1)$ & $11.6(2.1)$ \\
\hline$p$-value & & & 0.849 & 0.001 & 0.341 & 0.001 & 0.033 \\
\hline
\end{tabular}

The prevalence of chronic illness in the study population was similar to the national prevalence [28].

The results show that the following health conditions were associated with the overall quality of life among the elderly population in the Jaffna district: diabetes mellitus, musculoskeletal conditions, vision problems, hearing impairment, and bronchial asthma. These conditions were found to be associated with the QOL of elderly individuals in previous studies $[14,17]$.

Table 5 Proportions of participants with regular clinical follow-up and monthly doctor visits stratified by health conditions

\begin{tabular}{|c|c|c|c|c|c|}
\hline \multirow[t]{2}{*}{ Diseases } & \multirow[t]{2}{*}{$\begin{array}{l}\text { Number of elderly individuals } \\
\text { with that specific disease }\end{array}$} & \multicolumn{2}{|c|}{$\begin{array}{l}\text { Number of elderly individuals } \\
\text { regularly attending a clinic }\end{array}$} & \multicolumn{2}{|c|}{$\begin{array}{l}\text { Number of elderly individuals visiting } \\
\text { a doctor at least monthly }\end{array}$} \\
\hline & & n & $\%$ & $\mathbf{n}$ & $\%$ \\
\hline Muscular skeletal conditions & 181 & 33 & 18.2 & 41 & 22.6 \\
\hline Diabetes & 168 & 117 & 69.6 & 118 & 70.2 \\
\hline Hypertension & 153 & 84 & 54.9 & 91 & 59.4 \\
\hline Vision impairment & 132 & 38 & 28.8 & 47 & 35.6 \\
\hline Bronchial asthma & 80 & 23 & 28.7 & 22 & 27.5 \\
\hline Hearing impairment & 40 & 4 & 10 & 7 & 17.5 \\
\hline Hyperlipidaemia & 29 & 18 & 62.1 & 18 & 62.1 \\
\hline Heart disease & 18 & 15 & 83.3 & 16 & 88.9 \\
\hline Kidney disease & 7 & 2 & 28.5 & 3 & 42.8 \\
\hline Other & 13 & 3 & 23.1 & 4 & 30.8 \\
\hline
\end{tabular}


Table 6 Contributing factors to the QOL of participants

\begin{tabular}{|c|c|c|c|c|c|c|c|}
\hline \multirow[t]{2}{*}{ Factors } & \multirow[t]{2}{*}{ B- } & \multirow[t]{2}{*}{ S.E } & \multirow[t]{2}{*}{ Beta } & \multirow[t]{2}{*}{ t } & \multirow[t]{2}{*}{$P$-Value } & \multicolumn{2}{|c|}{$95 \% \mathrm{Cl} \mathrm{B}$} \\
\hline & & & & & & Lower & Upper \\
\hline (Constant) & 10.977 & .215 & & 50.943 & .000 & 10.554 & 11.400 \\
\hline Presence of diabetic mellitus & .469 & .198 & .090 & 2.368 & .018 & .080 & .857 \\
\hline Presence of musculoskeletal conditions & -.535 & .192 & -.105 & -2.779 & .006 & -.913 & -.157 \\
\hline Presence of vision impairment & -.040 & .182 & -.007 & -.222 & .824 & -.397 & .316 \\
\hline Presence of hearing impairment & -.431 & .305 & -.043 & -1.412 & .158 & -1.030 & .168 \\
\hline Presence of bronchial asthma & .114 & .223 & .016 & .511 & .609 & -.324 & .551 \\
\hline Presence of specific disease & -.416 & .202 & -.093 & -2.058 & .040 & -.813 & -.019 \\
\hline Having at least one ADL limitation & -2.012 & .272 & -.230 & -7.386 & .000 & -2.546 & -1.477 \\
\hline Satisfied with health status & 1.446 & .184 & .334 & 7.859 & .000 & 1.085 & 1.807 \\
\hline Visiting the doctor at least monthly & 1.035 & .187 & .209 & 5.521 & .000 & .667 & 1.403 \\
\hline Exposure to addictive substances & -.401 & .129 & -.093 & -3.115 & .002 & -.654 & -.148 \\
\hline
\end{tabular}

(Multiple linear regression $R=0.585, R^{2}=0.342$; Adjusted $R^{2}=0.344, \mathrm{SE}=1.747$ ) Significance $P<0.05$

(Higher score indicates better QOL)

Among these disease conditions, musculoskeletal conditions were the most prevalent complaint among the elderly population in Jaffna. This is in contrast to the finding from previous studies that hypertension is the health condition with the highest prevalence among the elderly population in Sri Lanka [18, 28]. This difference in disease prevalence is notable, as musculoskeletal conditions are associated with the dependency of the elderly; thus, they could be strongly associated with their QOL.

The prevalence of diabetes mellitus among the elderly population in Jaffna was high. Moreover, the prevalence of hypertension was considerably lower than the national prevalence. This difference may be associated with the differences in lifestyle practices and food preferences of the people in Jaffna compared to those of people living in other parts of the country.

The combination of multiple diseases is common among the elderly population [29]. Hypertension was previously found to be most commonly comorbid with diabetes mellitus [30]. This finding was supported by the current study, which showed that 86 elderly participants had both diabetes mellitus and hypertension and that this was the most common combination. Therefore, approximately one in ten elderly individuals in the Jaffna district have both diseases.

Surprisingly, having diabetes contributed to a higher quality of life. It was reported that the complications of chronic diseases are the main reason for the reduced quality of life among the elderly population. Hence, the absence of complications, active clinical follow-up, and regular monitoring could be possible reasons for this result. Notably, the Jaffna Teaching Hospital runs a Diabetic Centre where most of the diagnosed diabetic patients were registered. They receive regular follow-up and annual screening for associated long-term complications, and good health education is provided. This seems to be effective with regard to the management of complications associated with diabetes mellitus.

Elderly individuals with kidney disease reported the lowest overall quality of life compared to those with other diseases. A previous study conducted among elderly individuals in the Anuradhapura District also reported the same finding [14]. However, the contribution of the presence of kidney disease to the reduction in the quality of life of elderly individuals in Jaffna was not statistically significant. The prevalence of kidney disease is much higher in Anuradhapura District (15-23\%) [31], while it is very low in Jaffna District. This discrepancy may be due to geographical variations in disease prevalence. Furthermore, kidney disease among elderly individuals in Jaffna was most likely the result of complications of other diseases; thus, the effect of those diseases could mask the individual association of kidney disease with the QOL of elderly individuals in the Jaffna District.

It has been well documented by several previous researchers $[14,16,17,32-34]$ that morbidities are strongly associated with quality of life. Furthermore, in the current study, the overall QOL score was significantly lower among those who had a specific health condition than among those who did not have a specific health condition. Complications associated with chronic diseases may interfere with the standard of living of the elderly population. Further expenditures associated with health conditions can impose financial burdens, which can reduce the QOL of the elderly population. In addition, some disease conditions (psychiatric conditions and hearing and visual impairments) carry social stigma in the traditional society in Jaffna, which could contribute to a lower QOL. 
As shown by other studies [14, 17, 35], the overall QOL score of elderly individuals with ADL limitations was significantly lower than that of those without ADL limitations. Limitations in ADL tend to restrict the independence of elderly individuals, which can reduce their sense of wellbeing and, thus, ultimately reduce their quality of life. In the context of Jaffna, the rapid migration and death of younger people during the recent war has led to a greatly increased percentage of elderly individuals and a substantial reduction in the number of caregivers [25], which may further worsen the consequences of ADL limitations; thus, it could have significantly reduced the QOL of elderly individuals.

Satisfaction with one's health status was found to be an essential contributor to overall quality of life. The elderly individuals who reported being satisfied with their overall health had a higher quality of life score. This finding confirms that health is a vital component of quality of life, as has been indicated by several researchers $[14,16]$. In the current study, more than half of the participants reported being satisfied with their health. Furthermore, this positive finding could be associated with the relatively better health service availability in the Jaffna district. Satisfaction with their health may be associated with the physical and psychological wellness of the elderly population. In addition, elderly individuals who feel healthy might be more likely to participate in social activities. These factors might have enhanced their QOL.

Regarding clinical follow-up, elderly individuals who were attending a clinic regularly had a higher quality of life score than the others. Furthermore, the proportion of elderly individuals who were attending a clinic for hypertension and diabetes mellitus was relatively high.

Attending clinical follow-up was associated with a higher QOL in patients with those diseases, even though both diseases were found to be associated with a reduced quality of life in previous studies [36].

It is well known that the need for health services among the elderly population is high compared to other age groups [28]. It was reported that a higher frequency of doctor visits was associated with lower QOL [37]. However, in our study, it was found that elderly persons who visited a doctor at least once per month had significantly higher overall QOL scores than others. This is likely because regular visits to doctors could have enhanced their health and minimised the complications associated with ageing.

Some researchers have argued that the use of addictive substances decreases the quality of life of elderly individuals [38]. However, some other researchers have stated that this factor does not significantly affect the quality of life of elderly individuals [39]. In the current study, addictive substance use was found to negatively affect quality of life.

Jaffna District is known for its tobacco cultivation and cigar industry. One in ten farmers cultivate tobacco, and cigar smoking was is common among elderly individuals in Jaffna [40]. In addition, alcohol consumption is also common in Jaffna district [41], and native Palmyra toddy drinking is common among the elderly population [42]. Betel chewing is seen as a traditional practice, especially among older women in Jaffna. Exposure to addictive substances can lead to adverse health conditions. Furthermore, it can impose costs on elderly individuals. These factors could have contributed to the lower QOL among the elderly individuals who used addictive substances than those who did not.

\section{Limitations}

All the information was self-reported, without any crosschecks of clinical records. Elderly individuals who stated that they had been diagnosed with a disease by a doctor were recorded as having that disease. Therefore, underreporting could be a limitation.

\section{Conclusions}

The quality of life of the elderly population in Jaffna District was found to be average $(11.5 \pm 2.2$ out of 20$)$. As the elderly population is increasing rapidly, policies to improve the QOL of the elderly population are needed. Moreover, it has been found that chronic diseases are becoming increasingly common among elderly individuals in Jaffna District and that musculoskeletal complaints are the major problems in this population. Lifestyle modifications and healthy eating practices should be encouraged to reduce the prevalences of chronic diseases.

It was noted that the quality of life of elderly individuals with diabetes mellitus and hypertension was not as low as that of similar elderly individuals in previous studies. Furthermore, most elderly persons with diabetes mellitus and hypertension attended regular follow-up at clinics and visited a doctor frequently. This showed that these practices had a positive effect on their quality of life. These practices should be encouraged through the provision of additional assistance. It is also notable that the self-reported satisfaction of the participants with their health was higher than the results reported in other similar studies conducted in Sri Lanka.

The prevalence of exposure to addictive substances was found to be higher among the elderly population in Jaffna than the national prevalence, and it was found to be a contributing factor to a reduced QOL. Strict policies to control the use of addictive substances may enhance the QOL of the elderly population. Social values 
that encourage the use of addictive substances should be eliminated.

The following factors were found to independently contribute to a reduced quality of life among elderly individuals in Jaffna District: (a) the presence of specific health conditions, (b) the presence of musculoskeletal conditions, (c) limitations in activities of daily living, and (d) exposure to addictive substances. On the other hand, satisfaction with their health, visiting a doctor at least once a month, and having diabetes mellitus positively contributed to a better quality of life among the study participants.

Findings from this study can be generalised due to the use of a representative sample. The study had a clear objective, which was to determine the factors associated with QOL; therefore, the contribution of the factors highlighted in the study should be considered when developing interventions to improve the QOL of elderly individuals in the Jaffna district of Sri Lanka.

\section{Abbreviations}

QOL: Quality of life; ADL: Activity of daily living; WHOQOL: World Health Organisation Quality of Life

\section{Acknowledgements}

We acknowledge the elderly individuals who gave their consent to participate in this study and who gave their time to contribute to our research. Additionally, we acknowledge all Grama Niladaris (village heads) and the approximately one hundred Grama Niladari area volunteers who helped locate the residences of the elderly individuals.

\section{Authors' contributions}

SS conducted the study as the principal investigator. SS, SP, KS and LK supervised the study. All the authors contributed to the preparation and finalization of the manuscript. All authors read and approved the final manuscript.

\section{Funding}

No funding assistance was obtained for the study. This study was self-funded by the corresponding author.

\section{Availability of data and materials}

The data (questionnaires and datasets) of the current study are available from the corresponding author upon reasonable request.

\section{Declarations}

\section{Ethics approval and consent to participate}

Ethics approval was obtained from the Ethics Review Committee of the Faculty of Medicine of the University of Jaffna of Sri Lanka. Informed written consent was obtained from the participants prior to the interviews.

\section{Consent for publication}

Not applicable.

\section{Competing interests}

The authors declare that they have no competing interests.

\section{Author details}

${ }^{1}$ Department of Nursing, Faculty of Allied Health Sciences, University of Jaffna, Jaffna, Sri Lanka. ${ }^{2}$ Department of Community Medicine, Faculty of Medical Sciences, University of Sri Jayewardenepura, Nugegoda, Sri Lanka. ${ }^{3}$ Department of Physiology, Faculty of Medicine, University of Jaffna, Jaffna, Sri Lanka.
Received: 6 March 2020 Accepted: 25 February 2021

Published online: 06 March 2021

\section{References}

1. United Nations. World population prospects 2019: highlights: Department of Economic and Social Affaire, Population Division; 2019. https://population. un.org/wpp/Publications/Files/WPP2019_Highlights.pdf. Accessed 10 June 2020

2. Datta PP, Gangopadhyay N, Sengupta B. Association of Psychological Morbidity with socio-demographic characteristics among elderly: a crosssectional study from eastern India. Int J Med Public Health. 2013;3(2):94-9. https://doi.org/10.4103/2230-8598.115172.

3. Frank R. And Lichtenberg. The impact of biomedical innovation on longevity and health. Nordic JHealth Econ. 2017;5(1):45-57. https://doi.org/1 0.5617/njhe.1290.

4. De-Silva W. Indralal. Sri Lankan population change and demographic bonus challenges and opportunities in the new millennium (English), South Asia Human Development Sector report no. 37. Washington DC: World Bank; 2012. http://documents.worldbank.org/curated/en/600791468306873314/SriLankan-population-change-and-demographic-bonus-challenges-andopportunities-in-the-new-millennium

5. HelpAge International. HelpAge International Annual review-2015. 2015.

6. United Nations. (2015). World population ageing: Department of Economic and Social Affairs, Population Division; 2015. https://www.un.org/en/ development/desa/population/publications/pdf/ageing/WPA2015_Report. pdf. Accessed 10 June 2020

7. United Nations. World population ageing 2017 - highlights: Department of Economic and Social Affairs, Population Division; 2017. https://www.un.org/ en/development/desa/population/publications/pdf/ageing/WPA2017_ Highlights.pdf. Accessed 10 June 2020

8. United Nations. World population ageing: Department of Economic and Social Affairs, Population Division; 2013. https://www.un.org/en/ development/desa/population/publications/pdf/ageing/WorldPopulationA geing2013.pdf

9. United Nations. World population and future resources, population division. 2009.

10. Department of Census and Statistics. Sri Lanka demographic and health survey 2016. p. 2016

11. Siddhisena KA. Socio-economic implications of ageing in Sri Lanka: an overview. Oxford Institute of Ageing Working Papers. Oxford: Oxford Institute of Ageing; 2005. p. 1-27.

12. World Bank. Sri Lanka addressing the needs of an aging population: Human Development Unit, South Asia Region; 2008. https://openknowledge. worldbank.org/handle/10986/8105 License: CC BY 3.0 IGO

13. Khaje-Bishak Y, Payahoo L, Pourghasem B, Asghari JM. Assessing the quality of life in elderly people and related factors in Tabriz, Iran. J Caring Sci. 2014; 3(4):257-63. https://doi.org/10.5681/jcs.2014.028.

14. Rathnayake S, Siop S. Quality of life and its determinants among older people living in the rural community in Sri Lanka. Indian J Gerontol. 2015; 29(2):131-53.

15. Cadore EL, Izquierdo M. (2015). Exercise interventions in polypathological aging patients that coexist with diabetes mellitus: improving functional status and quality of life. Age. 2015;37(3):64. https://doi.org/10.1007/s11357015-9800-2.

16. Kanagaretnam T, Kamalarupan L, Thabotharan D, Coonghe PAD. Quality of life and its selected determinants among elderly people living in Nallur. Proc Jaffna Univ Int Res Conf. 2018;2018:198.

17. Kumar SG, Majumdar A, Pavithra G. Quality of life (QOL) and its associated factors using WHOQOL-BREF among elderly in urban Puducherry, India. J Clin Diagn Res. 2014;8(1):54-7. https://doi.org/10.7860/JCDR/2014/6996.3917.

18. Perera R. A sociological study on elderly care in an urban community in Sri Lanka. Proc Second Acad Sess. 2004;2004:142-6.

19. World Health Organization. World report on health and ageing. 2015.

20. WHOQOL Group (1998). Development of the World Health Organization WHOQOL-BREF quality of life assessment. Psychol Med. 1998;28:551-8.

21. Department of census and Statistics. District Statistical Hand Book Jaffna. 2016

22. Government Information Centre. Legal Aid for Elders. 2009. Retrieved on 25 may 2020, from http://gic.gov.lk/gic/index.php/en/component/info/?id=133 6\&catid=30\&task=info 
23. Department of Census and Statistics. Census of Population and Housing 2012. Sri Lanka: Provisional results, Department of Census and Statistics; 2013.

24. Perera ELSJ. Ageing population in Sri Lanka: emerging issues, needs, and policy implications, United Nations Population Fund. Sri Lanka: Technical Report October 2017; 2017

25. International Crisis Group. Sri Lanka's Authoritarian Turn: The Need forlnternational Action, Belgium, Asia Report. 2013(243).

26. Daniel WW. Biostatistics: A Foundation for analysis in the health sciences. 7th ed. New York: John Wiley \& Sons; 1999.

27. Skevington SM, Lotfy M, O'Connell KA. WHOQOL group. The World Health Organization's WHOQOL-BREF quality of life assessment: psychometric properties and results of the international field trial. A report from the WHOQOL group. Qual Life Res. 2004;13(2):299-310. https:/doi.org/10.1023/ B:OURE.0000018486.91360.00

28. Department of census and statistics. National Survey on Self-reported Health in Sri Lanka. 2014. http://www.statistics.gov.lk/social/National\%2 0Survey\%20on\%20Self-reported\%20Health-2014.pdf Accessed on 10 June 2020.

29. Quinones AR, Markwardt S, Botoseneanu A. Multimorbidity combinations and disability in older adults. J Gerontol A Biol Sci Med Sci. 2016;71(6):82330. https://doi.org/10.1093/gerona/glw035.

30. Kristy I, Hakima H, Patrick JH, Jinfei X, Xueying L, Samuel S, Engel SS, Moore LM, Rajpathak S. Prevalence and co-prevalence of comorbidities among patients with type 2 diabetes mellitus. Curr Med Res Opin. 2016;32(7):124352. https://doi.org/10.1185/03007995.2016.1168291.

31. Ranasinghe AV, Kumara GWGP, Karunarathna RH, et al. The incidence, prevalence and trends of Chronic Kidney Disease and Chronic Kidney Disease of uncertain aetiology (CKDu) in the North Central Province of Sri Lanka: an analysis of 30,566 patients. BMC Nephrol. 2019;20:338. https://doi. org/10.1186/s12882-019-1501-0.

32. Sowmiya KR, Nagarani. A Study on Quality of Life of Elderly Population in Mettupalayam, A Rural Area of Tamilnadu. Natl J Res Community Med. 2012; (1):123-77. https://doi.org/10.26727/NJRCM.2012.1.3.139-143.

33. Naing MM, Nanthamongkolchai S, Munsawaengsub C. Quality of life of the elderly people in Einme township Irrawaddy division, Myanmar. Asia J Public Health. 2010;2010(1):4-10.

34. McDaid O, Hanly MJ, Richardson K, et al. The effect of multiple chronic conditions on self-rated health, disability and quality of life among the older populations of Northern Ireland and the Republic of Ireland: a comparison of two nationally representative cross-sectional surveys. BMJ Open. 2013; 2013(3):e002571. https://doi.org/10.1136/bmjopen-2013-002571.

35. Uddin MA, Soivong P, Lasuka D, Juntasopeepun P. Factors related to quality of life among older adults in Bangladesh: a cross sectional survey. Nurs Health Sci. 2017;19(4):518-24. https://doi.org/10.1111/nhs.12385.

36. Poljicanin T, Ajdukovic D, Sekerija M, Pibernik-Okanovic M, Metelko Z, VuletiMavrinac G. (2010) Diabetes mellitus and hypertension have comparable adverse effects on health-related quality of life. BMC Public Health. 2010;10:12. https://doi.org/10.1186/1471-2458-10-12.

37. Kim ES, Park N, Sun JK, Smith J, Peterson C. Life satisfaction and frequency of doctor visits. Psychosom Med. 2014;76(1):86-93. https://doi.org/10.1097/ PSY.0000000000000024.

38. Layard R. Happiness: lessons from a new science. New York: Pengui; 2007.

39. Storeng SH, Sund ER, Krokstad S. Factors associated with basic and instrumental activities of daily living in elderly participants of a populationbased survey: the Nord-Trøndelag health study. Norway BMJ Open. 2018; 8(3):e018942. https://doi.org/10.1136/bmjopen-2017-018942.

40. Global Press Journal. Tobacco is Their Prized Crop. The Sri Lankan Government Is About to Ban It. 2019. Accessed on 19.05.20020 retrieved from https://globalpressjournal.com/asia/sri_lanka/tobacco-prized-crop-sri-la nkan-government-ban/

41. Asian tribune. In alcohol consumption - Jaffna District leads, second Nuwara Eliya \& Batticaloa third - President. (2016). retrieved on 28. 05.2020 retrieved from http://asiantribune.com/node/89146

42. Sri Lanka BRIEF. Jaffna booze paradise; alcoholism gripping the north.2015. retrieved on 28.05.2020 retrieved from https://srilankabrief.org/2015/06/ja ffna-booze-paradise-alcoholism-gripping-the-north/

\section{Publisher's Note}

Springer Nature remains neutral with regard to jurisdictional claims in published maps and institutional affiliations.

Ready to submit your research? Choose BMC and benefit from:

- fast, convenient online submission

- thorough peer review by experienced researchers in your field

- rapid publication on acceptance

- support for research data, including large and complex data types

- gold Open Access which fosters wider collaboration and increased citations

- maximum visibility for your research: over $100 \mathrm{M}$ website views per year

At $\mathrm{BMC}$, research is always in progress.

Learn more biomedcentral.com/submissions 